\title{
Wild-Type Mouse Models to Screen Antisense Oligonucleotides for Exon-Skipping Efficacy in Duchenne Muscular Dystrophy
}

\author{
Limin Cao, Gang Han, Ben Gu, HaiFang Yin* \\ Research Centre of Basic Medical Science and Department of Cell Biology, Tianjin Medical University, Heping District, Tianjin, China
}

\begin{abstract}
A readily available animal model is essential for rapidly identifying effective treatments for Duchenne muscular dystrophy (DMD), a devastating neuromuscular disorder caused by the lack of dystrophin protein, which results from frame-disrupting mutations in the DMD gene. Currently, the $m d x$ mouse is the most commonly used model for antisense oligonucleotide (AO)-mediated exon skipping pre-clinical studies, with a mild phenotype. However, the accessibility of $m d x$ mouse colonies particularly in developing countries can constrain research. Therefore in this study we explore the feasibility of using wildtype mice as models to establish exon-skipping efficiency of various DMD AO chemistries and their conjugates. Four different strains of wild-type mice and six different $A O$ chemistries were investigated intramuscularly and the results indicated that the same exon-skipping efficiency was achieved for all tested AOs as that from $m d x$ mice. Notably, levels of exon-skipping obtained in C57BL6 and $C 3 H$ and $m d x$ mice were most closely matched, followed by ICR and BALB/C mice. Systemic validation revealed that wild-type mice are less responsive to AO-mediated exon skipping than $m d x$ mice. Our study provides evidence for the first time that wild-type mice can be appropriate models for assessing DMD AO exonskipping efficiency with similar sensitivity to that of $m d x$ mice and this finding can further accelerate the development of effective DMD AOs.
\end{abstract}

Citation: Cao L, Han G, Gu B, Yin H (2014) Wild-Type Mouse Models to Screen Antisense Oligonucleotides for Exon-Skipping Efficacy in Duchenne Muscular Dystrophy. PLoS ONE 9(11): e111079. doi:10.1371/journal.pone.0111079

Editor: Gisela Nogales-Gadea, Institut de Recerca de la Santa Creu i Sant Pau, Spain

Received June 13, 2014; Accepted September 25, 2014; Published November 3, 2014

Copyright: ( 2014 Cao et al. This is an open-access article distributed under the terms of the Creative Commons Attribution License, which permits unrestricted use, distribution, and reproduction in any medium, provided the original author and source are credited.

Data Availability: The authors confirm that all data underlying the findings are fully available without restriction. All relevant data are within the paper and its Supporting Information files.

Funding: This work was supported by National Natural Science Foundation of China (Grant No. 81361128013, 81273420, and 81101340), Research Fund for the Doctoral Program of Higher Education of China (Grant No. 20111202110002) and Program for New Century Excellent Talents (NCET-10-0957). The funding sources had no involvement in study design, the collection, analysis and interpretation of data; in the writing of the report; and in the decision to submit the article for publication.

Competing Interests: The authors have declared that no competing interests exist.

* Email: haifangyin@tmu.edu.cn

\section{Introduction}

Duchenne muscular dystrophy (DMD) is an X-linked, lethal neuromuscular disorder caused by frame-disrupting mutations in the DMD gene, which ultimately result in the lack of functional dystrophin protein [1]. Currently there is no treatment available in clinic except for the use of steroid [2-4]. Numerous approaches for treating DMD are being investigated with antisense oligonucleotide (AO)-mediated exon-skipping therapeutics showing great promise from pre-clinical studies and phase II clinical trials [59]. However recent failure with Drisapersen from GSK and Prosensa phase III clinical trials highlights the importance of identifying safer and more effective AOs.

Animal models play a critical role in identifying effective treatments for DMD. Currently available DMD animal models include dystrophin-deficient mice $(m d x)$ [10-13], dystrophin/ utrophin double knock-out mice (DKO) [14], dystrophic dog $[15,16]$ and transgenic dystrophic pig [17], transgenic humanized $h D M D$ mice [18]. Although recently different variants of $m d x$ mice containing different mutations e.g. $m d x 2 c v, m d x 3 c v, m d x 4 c v$, $m d x 5 c v$ and exon 52 deficient $m d x 52$ have emerged and been extensively used for different purposes [19-21]. Among them, $m d x$ has been the most commonly used animal model for pre-clinical studies, particularly for DMD AO drug screen, which greatly contributes to ongoing clinical trials $[10,13,22,23]$. However, the accessibility and maintenance of $m d x$ mouse colonies are costly, particularly in developing countries, as $m d x$ mouse colonies are not widely distributed worldwide and also require special diets and higher-standard breeding condition compared to healthy wild-type mice, which can be a burden for researchers with limited resources. In addition, although in vitro models substantially facilitated the optimization of $\mathrm{AO}$ sequences for $\mathrm{DMD}$, in vitro models are not completely predictive of in vivo efficacy for some chemistry e.g. PMO (phosphorodiamidate morpholino oligomer) and PNA (peptide nucleic acid), which are notoriously difficult to transfect in vitro, but showing high activity in vivo [24-28]. Thus, a readily available and more cost-effective alternative in vivo model which allows researchers to identify uptake in different genetic background before optimization will further speed up the development of DMD AOs.

Therefore, we wished to investigate whether wild-type mice can be used to evaluate in vivo uptake and exon-skipping efficiency of new exon-skipping therapeutics before proceeding to optimization of a therapeutic regime in $m d x$ mice or appropriate animal models. 
Importantly, this would lower the financial barrier of innovation in the DMD field and lead to new therapeutic molecules for DMD and other genetic diseases $[29,30]$. Here we demonstrated that DMD AO exon-skipping efficacy in wild-type mice is comparable to that of $m d x$ mice via local intramuscular evaluation of six different $\mathrm{AO}$ chemistries, though systemic validation in $C 57 B L 6$ and $\mathrm{C} 3 \mathrm{H}$ with $\mathrm{PMO}$ revealed less effective exon skipping observed in wild-type mice than that of $m d x$ mice.

\section{Materials and Methods}

\section{Antisense oligonucleotide}

Six different $\mathrm{AO}$ chemistries were evaluated in this study. PMO was purchased from GeneTools (Oregon, USA), and peptideconjugated PMOs were synthesized with $>90 \%$ purity by Sarepta Therapeutics (formerly AVI Biopharma Inc, Oregon, USA). PNA and peptide-PNA conjugates were synthesized with high-performance liquid chromatography purification to $>90 \%$ purity by Panagene (Daejeon, Korea). Details of tested AOs were shown in Table 1. Different AO lengths and sequence positions with respect to the murine DMD exon 23 boundary region were shown in Table 1.

\section{Animals and intramuscular injection of AOs}

Four different strains of wild-type mice including C57BL6, $C 3 H, B A L B / C$ and $I C R$, and $m d x$ mice were used in all experiments ( 3 mice each group). The experiments were carried out in the animal unit, Tianjin Medical University (Tianjin, China) according to procedures authorized and specifically approved by the institutional ethical committee (Permit Number: SYXK 20090001). For intramuscular studies, TA (tibialis anterior) muscles of 6-8-week old experimental mouse were injected with various amounts of AOs in $40 \mu \mathrm{l}$ saline solution. For systemic injections, PMOs dissolved in $100 \mu \mathrm{l}$ saline buffer were injected into tail vein of $C 57 \mathrm{BL} 6, \mathrm{C} 3 \mathrm{H}$ and $m d x$ mice at the final dose of $25 \mathrm{mg} / \mathrm{kg}$. In order to examine the duration of dystrophin expression induced by various $\mathrm{AOs}$, mice were killed by cervical dislocation at desired time-points i.e. $48 \mathrm{hr}$, 2-week and 4-week after injection, and muscles tissues were snap-frozen in dry ice-cooled isopentane and stored at $-80^{\circ} \mathrm{C}$.

\section{RNA extraction and nested RT-PCR analysis}

Total RNA was extracted from tested muscle tissues with Trizol reagent as per manufacturer's protocol (Invitrogen, UK) and $400 \mathrm{ng}$ of RNA template was used for $20 \mu \mathrm{l}$ RT-PCR with OneStep RT- PCR kit (Qiagen, UK). The primer sequences for the initial RT-PGR were Exon20Fo: 5'-CAGAATTGTGGCAATTGCTGAG-3' and Exon26Ro: 5'-TTCTTCAGCTTG-

Table 1. Antisense oligonucleotide nomenclature.

\begin{tabular}{ll}
\hline Name & Sequence \\
\hline PMO & 5'-GGCCAAACCTCGGCTTACCTGAAAT - 3' \\
PNA & 5'-GGCCAAACCTCGGCTTACCTGAAAT-3' \\
2'OmePS & 5'-GGCCAAACCUCGGCUUACCU-3' \\
B-MSP-PMO & 5'-RXRRBRRXRRBRB-ASSLNIAX-ggccaaacctcggcttacctgaaat-3' \\
MOE25(PS) & 5'-GGCCAAACCTCGGCTTACCTGAAAT-3' \\
MSP & ASSLNIA \\
\hline
\end{tabular}

MSP, muscle-specific peptide and B - $\beta$-alanine [34].

doi:10.1371/journal.pone.0111079.t001
TGTCATCG-3' for amplification of mRNA from exons 20 to 26. The cycle conditions were $95^{\circ} \mathrm{C}$ for 30 seconds, $55^{\circ} \mathrm{C}$ for 30 seconds, and $72^{\circ} \mathrm{C}$ for 2 minutes for 25 cycles. The RT-PCR product $(0.8 \mu \mathrm{l})$ was then used for a nested PCR performed in $20 \mu \mathrm{l}$ with $0.5 \mathrm{U}$ Taq DNA polymerase (Invitrogen, UK). The primer sequences for the second round were Exon20F1: 5'CGCAGTCTACGACGCTATGAGAGG-3' and Exon 24R1: 5 'CGTGCCTTTAAGGCTTCGTT- 3 '. The cycle conditions were $94^{\circ} \mathrm{C}$ for 30 seconds, $57^{\circ} \mathrm{C}$ for 30 seconds, and $72^{\circ} \mathrm{C}$ for 2 minutes for 25 cycles. The products were examined by electrophoresis on a $2 \%$ agarose gel. The quantification of full-length and skipped RTPCR bands was based on densitometry of gel images and analyzed using ImageJ software (http://rsbweb.nih.gov/ij/).

\section{cDNA synthesis}

cDNA synthesis was carried out using Applied Biosystems High capacity cDNA reverse transcription kit. Reactions contained $2 \mu \mathrm{g}$ RNA, $1 \times$ RT Buffer, $4 \mathrm{mM}$ dNTP mix, RT random primers and MultiScribe reverse transcriptase in a final volume of $20 \mu \mathrm{l}$. The reaction was performed in a Techne TC-412 thermo cycler: $25^{\circ} \mathrm{C}$ for $10 \mathrm{~min}, 37^{\circ} \mathrm{C}$ for $120 \mathrm{~min}$, and $85^{\circ} \mathrm{C}$ for $5 \mathrm{~min}$.

\section{Quantitative PCR}

Real-time PCR were performed using an Applied Biosystems StepOnePlus qPCR System with SYBR Green dye. Reactions were carried out in $20 \mu \mathrm{l}$ reactions containing $100 \mathrm{ng}$ cDNA template, $2 \times$ master mix $(2 \times$ reaction buffer, $0.025 \mathrm{U} / \mu \mathrm{l} \mathrm{Taq}$ polymerase, $5 \mathrm{mM} \mathrm{MgCl} 2$ and $200 \mu \mathrm{M} \mathrm{dNTP}$ ) and $250 \mathrm{nM}$ primers. Cycling was initiated at $95^{\circ} \mathrm{C}$ for $10 \mathrm{~min}$, followed by 40 cycles of $95^{\circ} \mathrm{C}$ for $15 \mathrm{~s}, 60^{\circ} \mathrm{C}$ for $1 \mathrm{~min}$. Fluorescence was measured at the end of the elongation phase in each cycle. The homogeneity of amplicons was verified by melt curve.

Primers used to measure total DMD transcripts were designed within exons 20 and 21: (exon 20 forward: 5' ACG-ACG-CTATCA-GAG-CGA-AC and exon 21 reverse: 5'CAG-AAA-CATTGG-CCG-CTG-TG). Exon23-containing transcripts were amplified by exon 23 forward (5' ATT-GAG-GGG-CAC-TGGAAG-AA) and reverse primer spanning exon 24 (5' ACA-TCAACT-TCA-GCG-ATC-CA).

\section{Hematoxylin and eosin staining}

Routine haematoxylin and eosin staining was used to examine overall muscle morphology.

\section{Statistical analysis}

All data are reported as the mean \pm SEM. Statistical differences between different treated groups were evaluated by SigmaStat (Systat Software Inc. Chicago, IL, USA) and Mann-Whitney Rank Sum Test and Kruskal-Wallis One Way Analysis of Variance on Ranks were applied.

\section{Results}

\section{C57BL6 mice are good models for assessing DMD AO exon skipping efficacy}

To evaluate the feasibility of C57BL6 as an in vivo test system for AO-mediated exon skipping, we chose three well-studied and representative $\mathrm{AO}$ chemistries including $\mathrm{PMO}$ (phosphodiamidate morpholino oligomer), PNA (peptide nucleic acid) and 2'Ome PS (2'O-methyl RNA with phosphorothioate backbone) in our study [25,26,28,31-33]. Two microgram of PMO, $5 \mu \mathrm{g}$ of PNA or $5 \mu \mathrm{g}$ of 2'Ome PS was injected into TA muscles of adult C57BL6 mice and exon 23 skipping at RNA level was evaluated $48 \mathrm{hr}$ after 
A
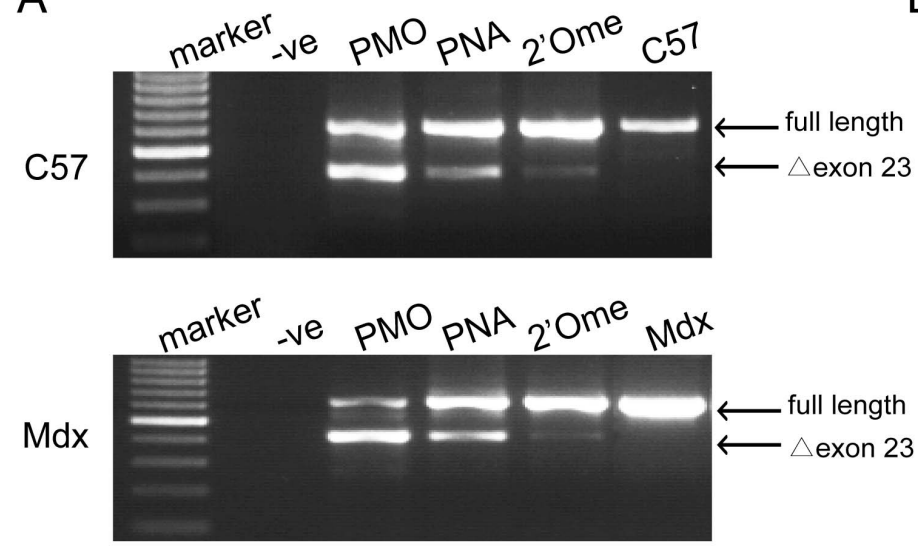

C

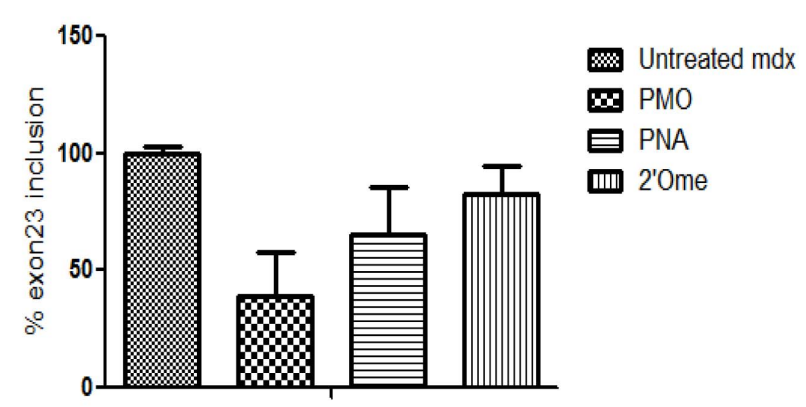

B

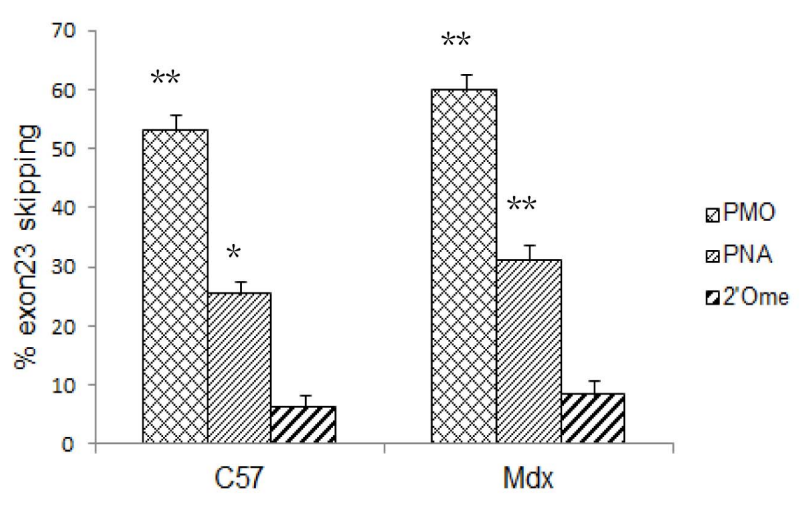

D

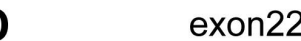

exon24

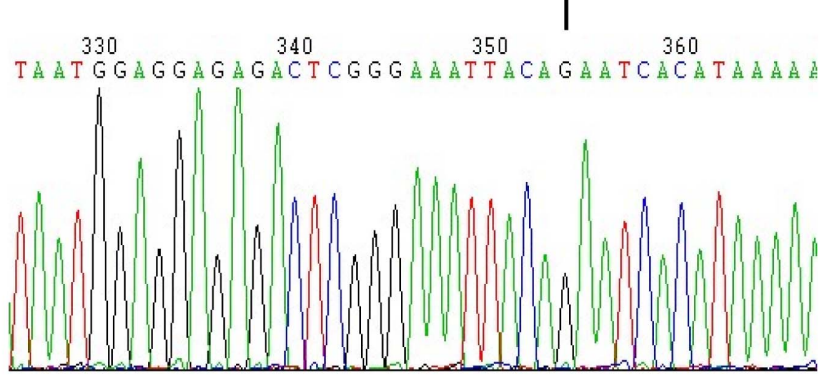

Figure 1. Effective exon skipping in C57BL6 and $m d x$ mice by local intramuscular injection of different AOs. (A) RT-PCR for detecting exon skipping at the RNA level with treated TA muscles $48 \mathrm{hr}$ after intramuscular injection of $2 \mu \mathrm{g} \mathrm{PMO}, 5 \mu \mathrm{g}$ PNA and $5 \mu \mathrm{g} 2^{\prime}$ Ome PS in C57BL6 and $m d x$ mice. The numbered $\Delta$ exon23 is for exon 23 skipping. -ve stands for RT-PCR blank control and the same below unless otherwise specified. (B) Quantitative analysis of exon skipping induced by different AOs in C57BL6 and $m d x$ mice ( ${ }^{* * P}<0.001 ; * P<0.05, n=3$ ). (C) Quantitative $P C R$ validation for detecting exon skipping at the RNA level with treated TA muscles $48 \mathrm{hr}$ after intramuscular injection in mdx mice. (D) Sequence analysis of the exon 23 skipped band in the RT-PCR products. doi:10.1371/journal.pone.0111079.g001

injection. RT-PCR results revealed that effective exon skipping can be achieved in C57BL6 with PMO and PNA, approximately $53.1 \%$ and $25.4 \%$, respectively (Fig. $1 \mathrm{~A}$ and B). Compared to PMO and PNA, much less efficient exon skipping was detected with 2'Ome PS, with only about 7.7\% (Fig. 1B). Subsequent sequencing confirmed exon 23 exclusion in murine DMD gene (Fig. 1D). When compared with $m d x$ mice (Fig. 1B), comparable level of exon skipping was achieved in C57BL6 for all tested AOs with the same order of efficiency, in which PMO showed the highest activity, followed by PNA and 2'Ome PS. Subsequent quantitative PGR results corroborated with the RT-PCR data and demonstrated the same pattern of exon skipping efficiency for PMO, PNA and 2'Ome PS in $m d x$ mice (Fig. 1C). Consistently, further evaluations of PMO and PNA derivatives e.g. B-MSPPMO (B refers to B peptide and MSP represents muscle-specific peptide), PNA-MSP and MOE PS (2'O-Methoxyethyl with phosphorothioate backbone), which were evaluated in $m d x$ mice previously $[25,27,34,35]$, in $C 57 B L 6$ revealed that effective exon skipping can be induced in C57BL6 at $48 \mathrm{hr}$ after local intramuscular injection, with B-MSP-PMO being better than PNA-MSP and MOE PS (Figs. S1A and B), suggesting that C57BL6 is a viable animal model for DMD AO screen.
Similar duration of exon skipping effects can be established between C57BL6 and $m d x$ mice

Given effective exon skipping observed in C57BL6 with PMO, PNA and 2'Ome PS, we wished to examine whether the similar duration of exon skipping effects can be induced in C57BL6 to that of $m d x$ mice as reported earlier [26,27]. The same amount of PMO $(2 \mu \mathrm{g})$ and PNA, 2'Ome PS $(5 \mu \mathrm{g})$ was injected into TA muscles of adult C57BL6 mice, respectively, and tissues were harvested at different time-points i.e. 2- and 4-week post-injection. Subsequent RT-PCR revealed almost complete exon 23 exclusion was obtained in TA muscles treated with PMO at 2-week which decreased at 4-week time-point, suggesting the peak time for measuring PMO exon skipping is 2-week post-injection. For PNA, consistent with our previous observation in $m d x$ mice [25], PNA was higher at the 4-week time-point in C57BL6, with about $41.3 \%$ exon 23 skipping (Fig. 2A and B). In contrast, there is no significant difference in exon skipping efficiency detected for 2'Ome PS between 2- and 4-week time-points in C57BL6, with 2week time-point $(9.5 \%)$ showing a marginal increase compared to 4-week time-point $(5.8 \%)$, corroborating with the earlier report [26]. Consistent with the data from $48 \mathrm{hr}$ time-point, 2'Ome PS shows much less activity than those of PMO and PNA. In addition, no inflammation was observed in treated TA muscles at any time-point tested as examined by Hematoxylin \& Eosin staining (Fig. S2). Overall, similar duration of exon skipping effects 
A

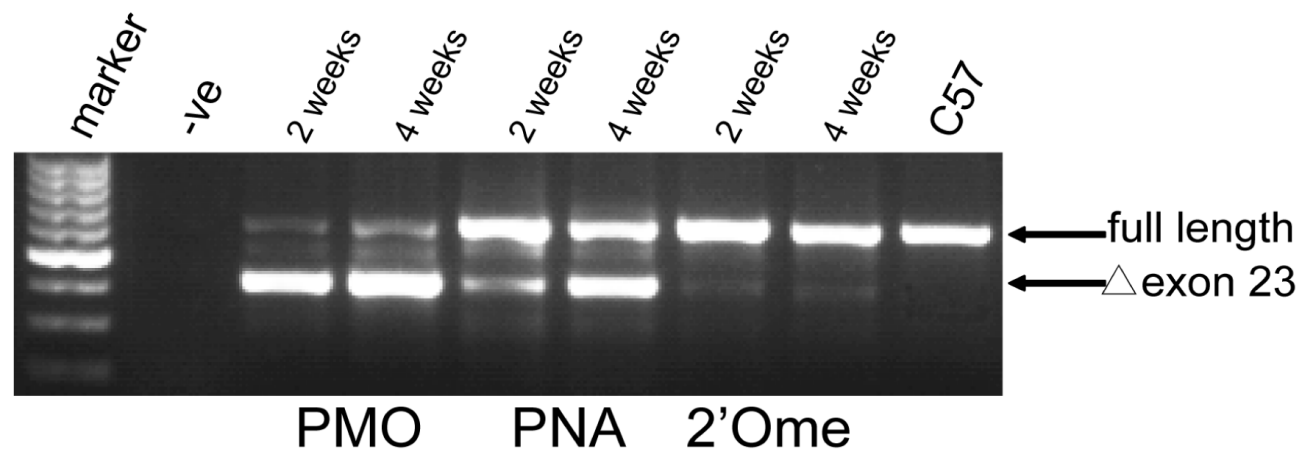

B

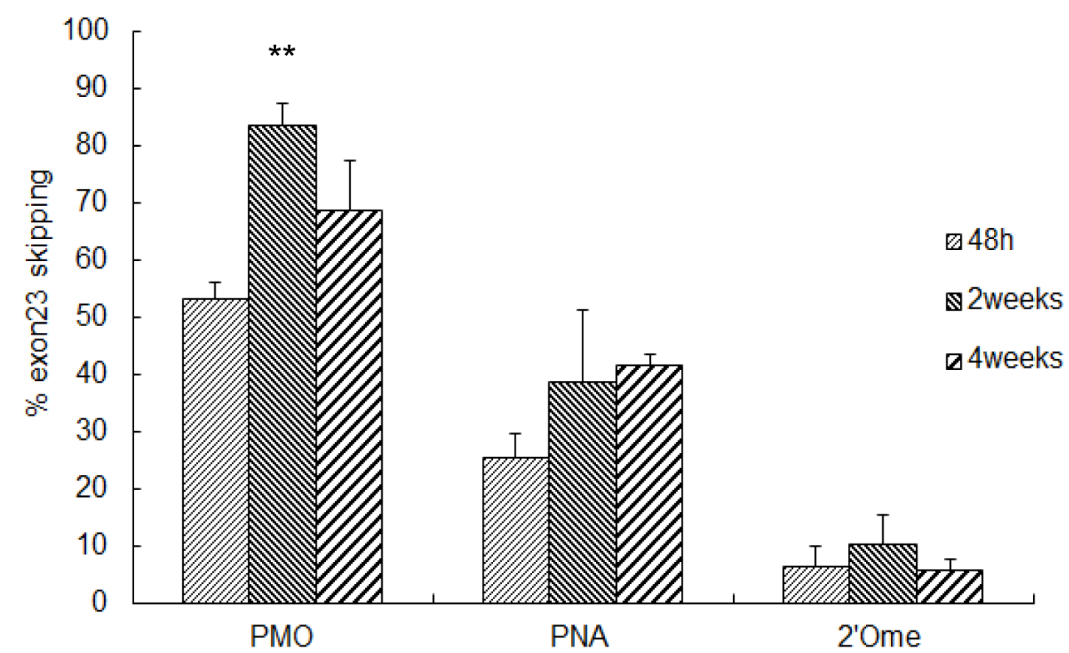

Figure 2. Duration of exon skipping effects in C57BL6 with different AOs by local intramuscular injection. (A) RT-PCR results for PMO, PNA and 2'Ome PS in C57BL6 at different time-points e.g. 2 and 4 weeks after local intramuscular injection. (B) Quantification of exon 23 skipping efficiency for PMO, PNA and 2'Ome PS at different time-points $(* * \mathrm{p}<0.001, \mathrm{n}=3$ ).

doi:10.1371/journal.pone.0111079.g002

was established in $C 57 B L 6$ to that of $m d x$ mice, further supporting C57BL6 is a good model system for DMD AO screen.

\section{Other wild-type strains are viable model systems for screening DMD AO}

Since effective exon skipping was achieved in C57BL6 with comparable level and similar duration of effects to that of $m d x$ mice, we extended our studies to other common laboratory strains including $I C R, C 3 H$ and $B A L B / C$. To examine the possibility and applicability of these mice as alternatives to $m d x$ mice for DMD AO screen, the same AOs including PMO, PNA and 2'Ome PS were injected into TA muscles of these three different strains of mice, respectively, under the same dosing regimen as did with C57BL6. Treated TA muscles were harvested $48 \mathrm{hr}$ after injection and assayed with RT-PCR. RT-PCR results indicated that significant exon skipping was induced for these three wild-type mice with all tested AOs (Fig. 3). Notably, the same order of exon skipping efficiency was achieved in these wild-type mice as those from C57BL6 and $m d x$ mice, with PMO showing the highest activity, followed by PNA and 2'Ome PS in ICR, C3H and $B A L B / C$ mice, respectively (Fig. $3 \mathrm{~B}, \mathrm{D}$ and $\mathrm{F}$ ), suggesting these wild-type mice are applicable for DMD AO screen and there is no major differences in uptake and efficacy of the AOs in between the strains.
Furthermore we cross-compared the exon skipping efficiency between four wild-type and $m d x$ mice based on the same AO chemistry. In regards to PMO, which demonstrated the highest level of exon skipping compared to PNA and 2'Ome PS in any tested animal model, similar exon skipping efficiency was achieved between $\mathrm{C} 3 \mathrm{H}$ and $m d x$ mice with the mean value of $63.7 \%$ and $60 \%$, respectively (Fig. 3). Second to $C 3 H$, significant exon skipping was detected in C57BL6 and ICR, approximately $53.1 \%$ and $58 \%$, respectively (Fig. 3G). Although slightly lower level of exon skipping was detected in $B A L B / C$ mice, the difference was not significant compared to $m d x$ mice. Of note, similar pattern was observed for PNA and 2'Ome PS, with comparable exon skipping achieved between $C 3 H$ and $m d x$ mice, followed by $C 57 B L 6$ and ICR and the least exon skipping detected in $B A L B / C$ mice, though the overall level for these two chemistries is lower than that of PMO.

Intravenous delivery of PMO in C57BL6 and $\mathrm{C} 3 \mathrm{H}$, at a low dose of $25 \mathrm{mg} / \mathrm{kg}$ for 3 weekly injections, revealed that detectable level of exon skipping was observed in quadriceps, abdominal and TA from treated $C 57 B L 6$ and $C 3 H$, though the overall level is lower than counterparts from treated $m d x$ mice under identical dosing regimen (Fig. S3). These data indicate that wild-type mice are responsive to AO-mediated exon skipping systemically, though to a less extent than that of $m d x$ mice. 
A

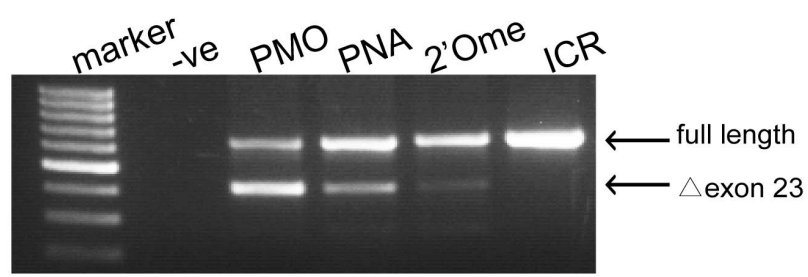

C

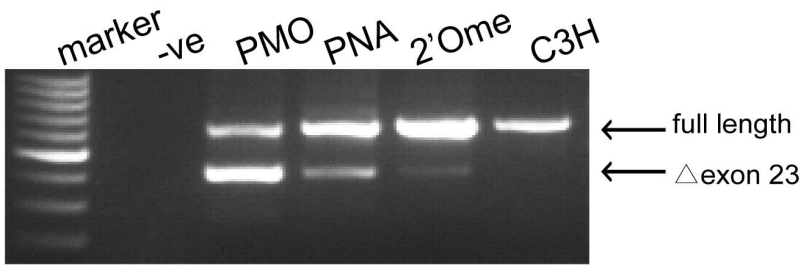

$\mathrm{E}$

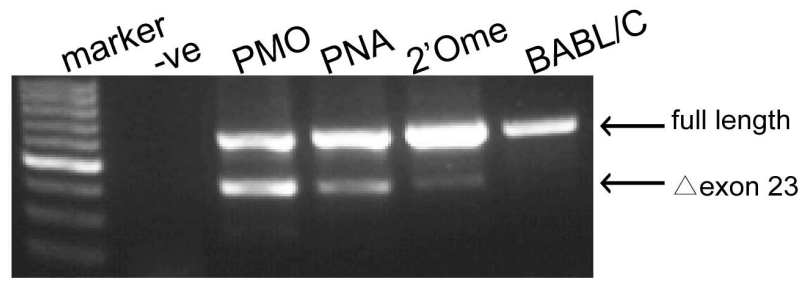

G

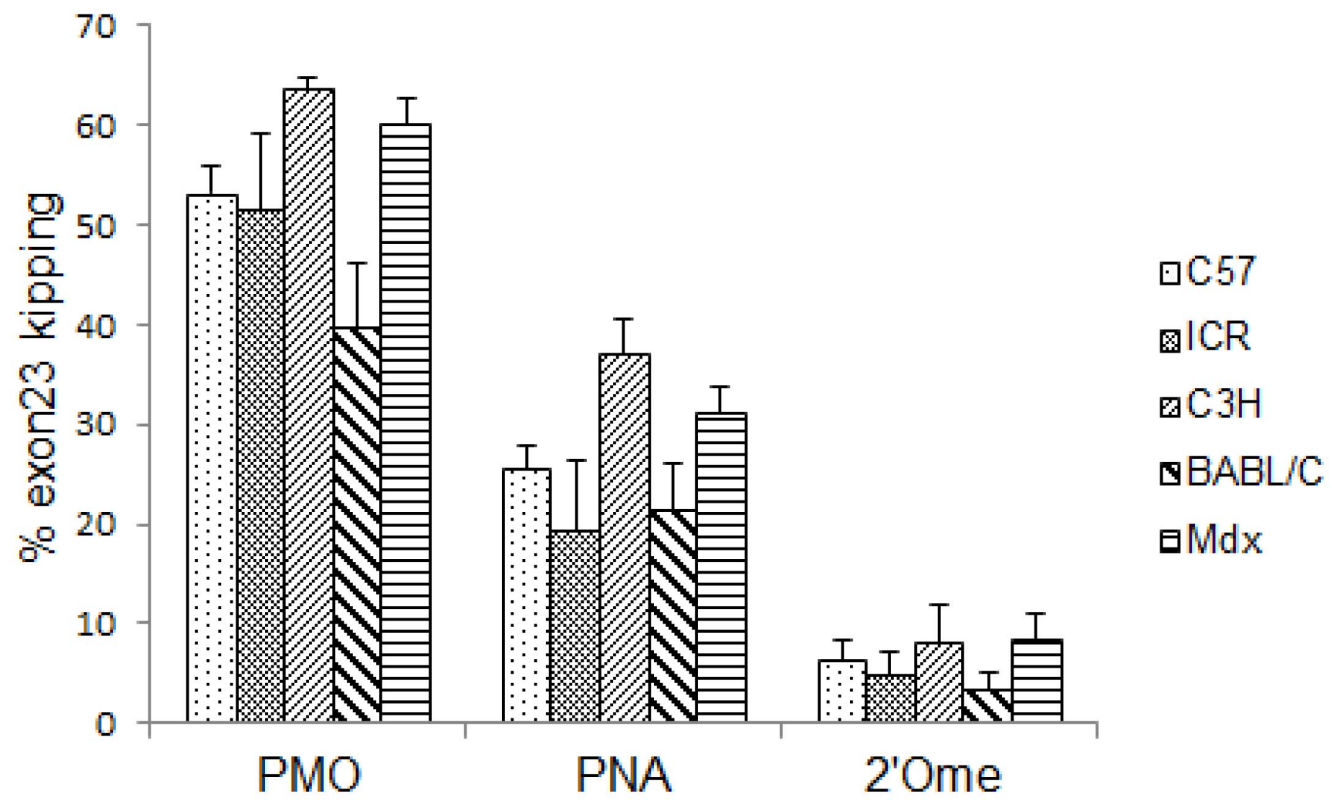

Figure 3. Efficient exon skipping in other wild-type mice by local intramuscular injection. (A) RT-PCR results for PMO, PNA and2' Ome PS in $\mathrm{C} 3 \mathrm{H}$ mice $48 \mathrm{hr}$ after local intramuscular injection. The numbered $\Delta$ exon23 is for exon 23 skipping. (B) Quantitative analysis of exon skipping induced by different $\mathrm{AOs}$ in $\mathrm{C} 3 \mathrm{H}$ mice $\left({ }^{*} \mathrm{P}<0.05, \mathrm{n}=3\right.$ ). (C) RT-PCR results for PMO, PNA and 2'Ome PS in ICR mice $48 \mathrm{hr}$ post-injection. (D) Quantitative analysis of exon skipping efficiency by different AOs in ICR mice ( ${ }^{* *} \mathrm{P}<0.001, \mathrm{n}=3$ ). (E) RT-PCR results for PMO, PNA and $2^{\prime} \mathrm{Ome}$ PS in $B A B L / C$ mice $48 \mathrm{hr}$ post-injection. (F) Quantitative analysis of exon skipping induced by different $A O s$ in $B A B L / C$ mice $\left({ }^{*} \mathrm{P}<0.05, \mathrm{n}=3\right)$. (G) Crosscomparison between different wild-type and $m d x$ mice per AO chemistry. doi:10.1371/journal.pone.0111079.g003

Taken together, our study demonstrated that wild-type mice can be used as alternative animal models for DMD AO screen and a means to ascertain variation in efficacy of AOs in mice with different genetic backgrounds, which can inform about the potential variation in therapeutic efficacy that might be present in the patient population.
B

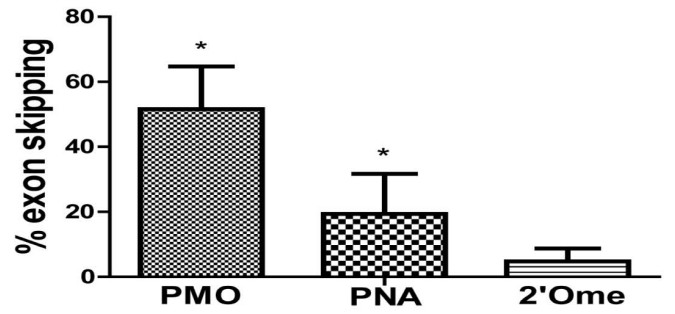

D
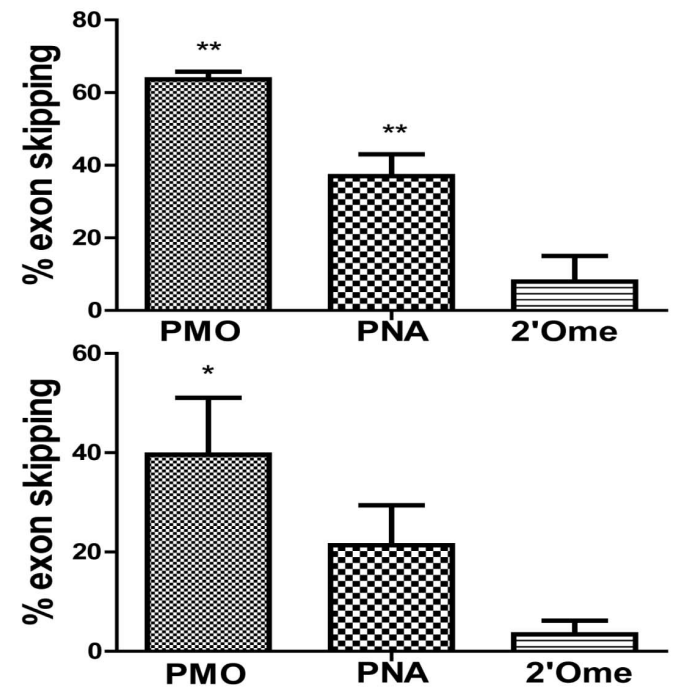
effective animal model is a critical component among others. In this report, we tested the feasibility and applicability of wild-type mice, which are easily accessible and require low maintenance cost, as in vivo models to evaluate DMD AO efficacy and distribution prior to studies in relevant disease models. This study implies that in vivo efficacy of AOs, which may not correlate to efficacy in cell culture, can also be used in wild-type mice for other exons in DMD in which specific models do not exist and even for other genes and for AOs of other functions.

Compared to the in vitro system, in vivo model presents with properly-assembled musculature including the presence of connective tissue and fibroblasts et al. More pertinently, transfection reagents are frequently required to deliver the $\mathrm{AOs}$ in cell culture while these could substantially mask the authentic property of tested AOs. Thus, in vitro efficacy does not reflect in vivo efficacy. This notion is supported by previous studies, in which $2^{\prime}$ Ome PS showed the greatest exon skipping activity in vitro compared to PMO and PNA but the least effective one in vivo locally and systemically $[24,27,38]$. In the current study, we reaffirmed findings from previous studies in $m d x$ mice that demonstrated better in vivo exon skipping efficacy of PMO and PNA compared to negatively charged RNA analog -2 'Ome PS, which can be attributed to their higher serum stability and sequence-specificity [27,31]. Peptide modifications, such as cell-penetrating peptides (CPPs) and targeting motifs are also more accurately assessed in vivo, irrespective of wild-type or $m d x$ mice [34,39,40]. Our findings further emphasize the importance of in vivo screen for DMD AOs, particularly for neutral PMO and PNA, which are notoriously difficult to transfect in vitro. Moreover, in vivo screen in wild-type mice can be used as a rapid drug screening platform as $48 \mathrm{hr}$ post-injection is sufficient to differentiate the potency of different AOs.

Although systemic evaluation of PMO in wild-type mice did not turn out as efficient as that from $m d x$ mice under identical dosing regimens, detectable level of exon skipping was observed in $C 57 B L 6$ and $C 3 H$ with a low dose of PMO, suggesting wild-type mice, particularly $C 57 B L 6$ and $C 3 H$, are viable animal models for systemic evaluation of DMD AOs. We speculate the difference between wild-type strains and $m d x$ mice can be attributed to the condition of muscle membrane e.g. membrane leakage in $m d x$ mice, which likely impacts on systemic delivery more than local administration by facilitating the vascular escape of AOs. In addition, we chose intravenous administration for our systemic studies since that it was reported previously that intravenous injection led to higher level of $\mathrm{AO}$ detention in body-wide tissues and increased exon skipping efficiency in muscles compared to intraperitoneal and subcutaneous administration in $m d x$ mice [41]. Furthermore, in our earlier report, we carried out a side-by-side comparison between intravenous and intraperitoneal injections in dystrophin/utrophin double knock-out mice $(D K O)$ and the data demonstrated that intravenous administration is more effective in enhancing AO-mediated exon skipping than intraperitoneal injection [42]. Therefore, the overall low level of exon skipping observed in systemic studies is likely due to the low dose applied and unlikely related to the delivery routes used.

Ultimately, except for the $h D M D$ mouse [18], all mouse models are primarily used to evaluate effects of backbone chemistries, peptide modifications and dosing regimens on delivery efficiency rather than efficacy of specific sequences because of sequence differences between human and murine $D M D$ genes. Functional improvement in DMD mice, while useful in previous studies to demonstrate that restoration of dystrophin expression at a specific level can lead to functional improvement, is not as crucial for the above-mentioned uses for a variety of reasons. First, these mice do not fully recapitulate human pathology, so functional improvements may not be translatable; second, the dystrophin restored by exon skipping in humans and mice have different domains removed so it may have different functional effects; third, sequence-specific differences may have a bigger role to play on exon skipping once the $\mathrm{AO}$ is within the cell, thus the inability to test human sequences in mice means the results are not directly translatable. Moreover, the differences in systemic distribution between wild-type strains may provide insights into the variation that will be present in human patients and can inform better designs for AOs. Thus, our study indicates that it is beneficial financially and therapeutically to evaluate AO chemistry and modifications in wild-type strains despite the inability to assess functional improvements.

\section{Conclusions}

In summary, we demonstrated that wild-type mice are a practicable system for DMD AO screen locally and systemically, with wild-type mice showing less responsive to AO-mediated exon skipping than $m d x$ mice systemically. The application of this model system can potentially open up a new avenue for DMD study and further accelerate the development of $\mathrm{DMD} \mathrm{AOs}$ for the treatment of DMD patients.

\section{Supporting Information}

Figure S1 Evaluation of other AO chemistries in C57BL6 mice intramuscularly. (A) RT-PCR for detecting exon skipping at the RNA level with treated TA muscles $48 \mathrm{hr}$ after intramuscular injection of $2 \mu \mathrm{g}$ B-MSP-PMO, $5 \mu \mathrm{g}$ PNA-MSP and $5 \mu \mathrm{g}$ MOE. The numbered $\Delta$ exon23 is for exon 23 skipping. (B) Quantitative evaluation of exon skipping induced by different AOs in C57BL6 $(* * \mathrm{P}<0.001$ and $* \mathrm{P}<0.05, \mathrm{n}=3)$.

(TIF)

Figure S2 Routine hematoxylin and eosin staining for examining muscle morphology. Hematoxylin and eosin staining of TA tissue sections from treated C57BL6 mice with $2 \mu \mathrm{g}$ PMO, $5 \mu \mathrm{g}$ PNA and $5 \mu \mathrm{g} 2^{\prime}$ Ome PS by local injection at different time-points e.g. $48 \mathrm{hr}, 2$ and 4 weeks after injection, and C57BL6 normal controls. Scale Bar $=100 \mu \mathrm{m}$. No difference was observed between treated and untreated $m d x$ mice.

(TIF)

Figure S3 Systemic evaluation of PMO in wild-type and $m d x$ mice. (A) RT-PGR results for systemic validation in C57BL6, $\mathrm{C} 3 \mathrm{H}$ and $m d x$ mice with PMO intravenously, at a low dose of $25 \mathrm{mg} / \mathrm{kg}$ for 3 weekly injections. The numbered $\Delta$ exon23 is for exon 23 skipping. (B) Quantitative evaluation of exon skipping in body-wide muscles in treated $C 57 B L 6, C 3 H$ and $m d x$ mice $(* * \mathrm{P}<$ $0.001, \mathrm{n}=3)$.

(TIF)

\section{Acknowledgments}

The authors acknowledge Dr Yiqi Seow (Biomedical Sciences Institutes, A*STAR, Singapore) and Dr Mary McMenamin (University of Oxford) for critical reading of the manuscript.

\section{Author Contributions}

Conceived and designed the experiments: HY. Performed the experiments: LC GH BG. Analyzed the data: LC GH. Wrote the paper: HY LC. 


\section{References}

1. Hoffman EP, Knudson CM, Campbell KP, Kunkel LM (1987) Subcellular fractionation of dystrophin to the triads of skeletal muscle. Nature 330: 754-758.

2. Angelini C, Peterle E (2012) Old and new therapeutic developments in steroid treatment in Duchenne muscular dystrophy. Acta Myol 31: 9-15.

3. Bhattacharya S, Nayak A, Schiavone M, K Bhattacharya S (2004) Solubilization and concentration of carbon dioxide: novel spray reactors with immobilized carbonic anhydrase. Biotechnol Bioeng 86: 37-46.

4. Tidball JG, Wehling-Henricks M (2004) Evolving therapeutic strategies for Duchenne muscular dystrophy: targeting downstream events. Pediatr Res 56: 831-841.

5. Cirak S, Arechavala-Gomeza V, Guglieri M, Feng L, Torelli S, et al. (2011) Exon skipping and dystrophin restoration in patients with Duchenne muscular dystrophy after systemic phosphorodiamidate morpholino oligomer treatment: an open-label, phase 2, dose-escalation study. Lancet 378: 595-605.

6. Goemans NM, Tulinius M, van den Akker JT, Burm BE, Ekhart PF, et al. (2011) Systemic administration of PRO051 in Duchenne's muscular dystrophy. N Engl J Med 364: 1513-1522.

7. Kinali M, Arechavala-Gomeza V, Feng L, Girak S, Hunt D, et al. (2009) Local restoration of dystrophin expression with the morpholino oligomer AVI-4658 in Duchenne muscular dystrophy: a single-blind, placebo-controlled, dose-escalation, proof-of-concept study. Lancet Neurol 8: 918-928.

8. Goyenvalle A, Seto JT, Davies KE, Chamberlain J (2011) Therapeutic approaches to muscular dystrophy. Hum Mol Genet 20: R69-78.

9. Extance A (2009) Targeting RNA: an emerging hope for treating muscular dystrophy. Nat Rev Drug Discov 8: 917-918.

10. Ahmad A, Brinson M, Hodges BL, Chamberlain JS, Amalfitano A (2000) Mdx mice inducibly expressing dystrophin provide insights into the potential of gene therapy for duchenne muscular dystrophy. Hum Mol Genet 9: 2507-2515.

11. Allamand V, Campbell KP (2000) Animal models for muscular dystrophy: valuable tools for the development of therapies. Hum Mol Genet 9: 2459-2467.

12. Mann CJ, Honeyman K, Cheng AJ, Ly T, Lloyd F, et al. (2001) Antisenseinduced exon skipping and synthesis of dystrophin in the mdx mouse. Proc Natl Acad Sci U S A 98: 42-47.

13. Wu B, Lu P, Cloer C, Shaban M, Grewal S, et al. (2012) Long-term rescue of dystrophin expression and improvement in muscle pathology and function in dystrophic mdx mice by peptide-conjugated morpholino. Am J Pathol 181: 392 400.

14. Rafael JA, Townsend ER, Squire SE, Potter AC, Chamberlain JS, et al. (2000) Dystrophin and utrophin influence fiber type composition and post-synaptic membrane structure. Hum Mol Genet 9: 1357-1367.

15. Sharp NJ, Kornegay JN, Van Camp SD, Herbstreith MH, Secore SL, et al. (1992) An error in dystrophin mRNA processing in golden retriever muscular dystrophy, an animal homologue of Duchenne muscular dystrophy. Genomics 13: $115-121$.

16. Howell JM, Fletcher S, Kakulas BA, O’Hara M, Lochmuller H, et al. (1997) Use of the dog model for Duchenne muscular dystrophy in gene therapy trials. Neuromuscul Disord 7: 325-328.

17. Klymiuk N, Blutke A, Graf A, Krause S, Burkhardt K, et al. (2013) Dystrophindeficient pigs provide new insights into the hierarchy of physiological derangenments of dystrophic muscle. Hum Mol Genet 22(21): 4368-82.

18. Bremmer-Bout M, Aartsma-Rus A, de Meijer EJ, Kaman WE, Janson AA, et al. (2004) Targeted exon skipping in transgenic hDMD mice: A model for direct preclinical screening of human-specific antisense oligonucleotides. Mol Ther 10: 232-240.

19. Araki E, Nakamura K, Nakao K, Kameya S, Kobayashi O, et al. (1997) Targeted disruption of exon 52 in the mouse dystrophin gene induced muscle degeneration similar to that observed in Duchenne muscular dystrophy. Biochem Biophys Res Commun 238: 492-497.

20. Im WB, Phelps SF, Copen EH, Adams EG, Slightom JL, et al. (1996) Differential expression of dystrophin isoforms in strains of $\mathrm{mdx}$ mice with different mutations. Hum Mol Genet 5: 1149-1153.

21. Aoki Y, Nakamura A, Yokota T, Saito T, Okazawa H, et al. (2010) In-frame dystrophin following exon 51-skipping improves muscle pathology and function in the exon 52-deficient mdx mouse. Mol Ther 18: 1995-2005.
22. Grounds MD, Radley HG, Lynch GS, Nagaraju K, De Luca A (2008) Towards developing standard operating procedures for pre-clinical testing in the $\mathrm{mdx}$ mouse model of Duchenne muscular dystrophy. Neurobiol Dis 31: 1-19.

23. van Deutekom JC, Janson AA, Ginjaar IB, Frankhuizen WS, Aartsma-Rus A, et al. (2007) Local dystrophin restoration with antisense oligonucleotide PRO051. N Engl J Med 357: 2677-2686.

24. Wang Q Yin H, Camelliti P, Betts C, Moulton H, et al. (2010) In vitro evaluation of novel antisense oligonucleotides is predictive of in vivo exon skipping activity for Duchenne muscular dystrophy. J Gene Med 12: 354-364.

25. Alter J, Lou F, Rabinowitz A, Yin H, Rosenfeld J, et al. (2006) Systemic delivery of morpholino oligonucleotide restores dystrophin expression bodywide and improves dystrophic pathology. Nat Med 12: 175-177.

26. Lu QL, Mann CJ, Lou F, Bou-Gharios G, Morris GE, et al. (2003) Functional amounts of dystrophin produced by skipping the mutated exon in the $\mathrm{mdx}$ dystrophic mouse. Nat Med 9: 1009-1014.

27. Yin H, Betts C, Saleh AF, Ivanova GD, Lee H, et al. (2010) Optimization of peptide nucleic acid antisense oligonucleotides for local and systemic dystrophin splice correction in the mdx mouse. Mol Ther 18: 819-827.

28. Yin H, Lu Q, Wood M (2008) Effective exon skipping and restoration of dystrophin expression by peptide nucleic acid antisense oligonucleotides in $\mathrm{mdx}$ mice. Mol Ther 16: 38-45.

29. Islamian JP, Mohammadi M, Baradaran B (2014) Inhibition of human esophageal squamous cell carcinomas by targeted silencing of tumor enhancer genes: an overview. Cancer Biol Med 11: 78-85.

30. Zheng H, Liu JY, Song FJ, Chen KX (2013) Advances in circulating microRNAs as diagnostic and prognostic markers for ovarian cancer. Cancer Biol Med 10: 123-130.

31. Heemskerk HA, de Winter CL, de Kimpe SJ, van Kuik-Romeijn P, Heuvelmans $\mathrm{N}$, et al. (2009) In vivo comparison of 2'-O-methyl phosphorothioate and morpholino antisense oligonucleotides for Duchenne muscular dystrophy exon skipping. J Gene Med 11: 257-266.

32. Kendall GC, Mokhonova EI, Moran M, Sejbuk NE, Wang DW, et al. (2012) Dantrolene enhances antisense-mediated exon skipping in human and mouse models of Duchenne muscular dystrophy. Sci Transl Med 4: 164ra160.

33. Geary RS, Watanabe TA, Truong L, Freier S, Lesnik EA, et al. (2001) Pharmacokinetic properties of 2'-O-(2-methoxyethyl)-modified oligonucleotide analogs in rats. J Pharmacol Exp Ther 296: 890-897.

34. Yin H, Moulton HM, Betts C, Seow Y, Boutilier J, et al. (2009) A fusion peptide directs enhanced systemic dystrophin exon skipping and functional restoration in dystrophin-deficient mdx mice. Hum Mol Genet 18: 4405-4414.

35. Yang L, Niu H, Gao X, Wang Q, Han G, et al. (2013) Effective exon skipping and dystrophin restoration by $2^{\prime}-0$-methoxyethyl antisense oligonucleotide in dystrophin-deficient mice. PLoS One 8: e61584.

36. Kang JK, Malerba A, Popplewell L, Foster K, Dickson G (2011) Antisenseinduced myostatin exon skipping leads to muscle hypertrophy in mice following octa-guanidine morpholino oligomer treatment. Mol Ther 19: 159-164.

37. Goyenvalle A, Davies KE (2011) Challenges to oligonucleotides-based therapeutics for Duchenne muscular dystrophy. Skelet Muscle 1: 8.

38. Malerba A, Sharp PS, Graham IR, Arechavala-Gomeza V, Foster K, et al. (2011) Chronic systemic therapy with low-dose morpholino oligomers ameliorates the pathology and normalizes locomotor behavior in mdx mice. Mol Ther 19: $345-354$.

39. Yin H, Saleh AF, Betts C, Camelliti P, Seow Y, et al. (2011) Pip5 transduction peptides direct high efficiency oligonucleotide-mediated dystrophin exon skipping in heart and phenotypic correction in mdx mice. Mol Ther 19: 1295-1303.

40. Moulton HM, Moulton JD (2010) Morpholinos and their peptide conjugates: therapeutic promise and challenge for Duchenne muscular dystrophy. Biochim Biophys Acta 1798: 2296-2303.

41. Heemskerk H, de Winter C, van Kuik P, Heuvelmans N, Sabatelli P, et al. (2010) Preclinical PK and PD studies on 2'-O-methyl-phosphorothioate RNA antisense oligonucleotides in the mdx mouse model. Mol Ther 18: 1210-1217.

42. Crisp A, Yin H, Goyenvalle A, Betts C, Moulton HM, et al. (2011) Diaphragm rescue alone prevents heart dysfunction in dystrophic mice. Hum Mol Genet 20: $413-421$. 